\title{
Is there a Recommendation for Safety in the Practice of Regional Anesthesia?
}

Dear Editor in chief, Dr. Mário J. da Conceição, I have read with great interest the article published in the Brazilian Journal of Anesthesiology (RBA) guiding professionals on safety in the practice of regional blocks ${ }^{1}$. I congratulate the authors for the effort and seriousness with which they handled this subject.

I would like to make some remarks about three topics:

\section{References}

Anesthesia is a medical procedure modified throughout the years due to technological and pharmacological innovations, being reasonable to consider that techniques used nowadays are not the same used in the past. Observing the references, it is noticeable that the authors used publications that analyzed patients undergoing researches involving anesthesia in previous decades. The text does not clarify how authors acted in face of such limitation or whether it was considered in any moment of the analysis of the articles included in the recommendations. Would it be possible to clarify this?

The strategy used to identify the included articles does not make it clear which step or moment enabled the use of book chapters. A chapter of a book was used, but observing its content it seems that it addresses the American pharmacopoeia and not specifically the practice of anesthesia ${ }^{2}$.

\section{Initial theoretical grounding}

The authors' intention was to approach infectious complications related to regional block, but it is important to highlight that these complications are rare; "There is no clear evidence in the literature on the frequency of such complications (D)" and "Also rare is the drug administration errors in regional block (?)". Therefore, the creation of recommendations without previously knowing the real or estimated frequency of events may be seen with reservations. Would it be possible the authors to carry out a research in Brazil together with the Sociedade Brasileira de Anestesiologia (Brazilian Anesthesiology Society) to identify the current frequency of such events, making the consult to the recommendations more feasible?
The authors use epidemiological series to justify that, even in the absence of published information, the frequency of infectious complications and accidents are rising. Nevertheless, the studies used as reference were conducted in the 1980s and 1990s, remaining doubtful the current state of events ${ }^{3-6}$.

\section{Recommendation degrees and evidences impact}

There are recommendations based only in publications with level of evidence $D$ leading the authors to have a less affirmative position in the text. Thus, some recommendations were a little dubious being necessary for the authors to better explain the topic.

Some examples: "..., except in the most extraordinary circumstances, neuraxial blockade should not be performed in patients with untreated systemic infection."; "Consultation of an infectologist is recommended to facilitate early and effective antibiotic therapy"; and "ANVISA (National Health Surveillance Agency) does not recommend reprocessing of materials for use in regional anesthesia,...". The concept of "extraordinary circumstance" was not clear in the text; if the consultation of an infectologist may influence in decision making on choosing the anesthetic technique and even if there are still hospitals that use reprocessed material in Brazil.

The authors did not make reference to the use of systematic reviews and meta-analysis, being necessary to understand whether there was any exclusion criteria to set aside this type of research, or if there is no research of this type analyzing this topic.

All in all, there are recommendations and they must be used with patients in the daily practice, but some points must be seen with reservations due to the power of evidences that generated certain recommendations especially those based solely on evidence level $D$. We need to know the frequency of infectious anesthetic complications in Brazil.

Fabiano Timbó Barbosa, Professor Universidade Federal de Alagoas Anesthesiology Graduate Degree 


\section{REFERÊNCIAS / REFERENCES}

1. Fernandes CR, Fonseca NM, Rosa DM et al. - Recomendações da Sociedade Brasileira de Anestesiologia para segurança em anestesia regional. Rev Bras Anestesiol, 2011;61:668-694.

2. USP Chapter 797 with proposed revisions 2006 - http://www.usp.org/pdf/ EN/USPNF/PF797redline.pdf. 
3. Moen $\mathrm{V}$, Dahlgren $\mathrm{N}$, Irestedt $\mathrm{L}$ - Severe neurological complications after central neuraxial blockades in Sweden 1990-1999. Anesthesiology, 2004;101:950-959.

4. Horlocker TT, McGregor DG, Matsushige DK et al. - A retrospective review of 4,767 consecutive spinal anesthetics: central nervous system complications. Perioperative Outcomes Group. Anesth Analg, 1997;84(3):578-584.
5. Wang LP, Hauerberg J, Schmidt JF - Incidence of spinal epidural abscess after epidural analgesia: a national 1-year survey. Anesthesiology, 1999;91(6):1928-1936.

6. Aromaam U, Lahdensuu DA, Cozanitis S-Severe complications associated with epidural and spinal anaesthesias in Finland 1987-1993. A study based on patient insurance claims. Acta Anaesthesiol Scand, 1997;41:445-452. 